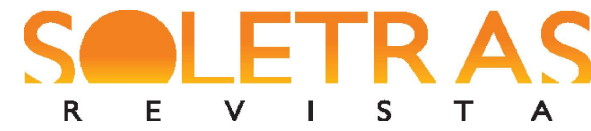

\title{
A sequência didática no contexto do Ensino Fundamental: relações entre a concepção docente e o planejamento de atividades
}

\author{
Maria Fátima Alves ${ }^{1}$ \\ Vanderléia Lucena Meira ${ }^{2}$
}

\begin{abstract}
Resumo: A sequência didática (SD) é um meio eficaz para transpor didaticamente os gêneros textuais, tornando-os ensináveis em situações efetivas de comunicação. Esta pesquisa se classifica como um estudo de caso (GIL, 1999) e busca analisar a relação entre a concepção docente e o planejamento de uma sequência didática por uma professora da rede pública de Ensino da cidade de Campina GrandePB e que participa de um curso de formação continuada. Os dados que constituem o corpus do estudo se originam de uma questão aberta sobre SD, além de uma SD planejada por ela. Como quadro teórico, o estudo se ancora nos trabalhos de BRONCKART (1997, 1999, 2010); MIRANDA (2015); MACHADO e CRISTOVÃO (2009); HILA (2009); e NOVERRAZ, SCHNEUWLY E DOLZ (2004). Os resultados apontam que o conceito de SD da docente se aproxima mais de uma perspectiva educacional do que da área da linguística, nos moldes do grupo genebrino, já que ela a concebe apenas como uma prática metodológica para trabalhar os conteúdos. Apesar disso, as atividades que constituem a SD analisada são bem desenvolvidas e abordam os conteúdos de forma producente, relacionando-os com os objetivos propostos e tomando o gênero como um megainstrumento para o trabalho com a linguagem.
\end{abstract}

Palavras-chave: Ensino de Gêneros. Transposição Didática. Sequência Didática.

\section{Introdução}

Considerando a relevância que os gêneros textuais assumem no ensino de Língua Portuguesa como instrumento mediador da ação dos alunos no mundo, por meio das práticas de linguagem, e considerando a relevância da sequência didática como uma ferramenta imprescindível à apropriação dos gêneros textuais no contexto escolar, entendemos que é fundamental que o professor tenha clareza sobre o que é uma sequência didática e saiba como elaborá-la de forma que possibilite aos aprendizes o uso efetivo dos gêneros na escola e fora dela.

$\mathrm{O}$ conceito de sequência didática (doravante $\mathrm{SD}$ ), entendido como "atividades escolares organizadas, de maneira sistemática, em torno de um gênero textual oral ou escrito", foi proposto por Dolz, Noverraz e Schneuwly (2001) e divulgado no Brasil com a publicação

\footnotetext{
${ }^{1}$ Doutora em Linguística pela UFPE. Professora da Unidade Acadêmica de Educação (UAED) e do Programa de Pós-Graduação em Linguagem e Ensino (POSLE) da UFCG, PB, Campina Grande, Brasil. E-mail: fatima.uaed@gmail.com

${ }^{2}$ Especialista em Ensino de Língua Portuguesa na Educação Básica (CEELP) pela Universidade Federal de Campina Grande (UFCG). Mestranda do Programa de Pós-Graduação em Linguagem e Ensino (POSLE) da UFCG, PB, Campina Grande, Brasil. E-mail: vanderleialucena.ped@gmail.com
} 
do artigo "Sequências didáticas para o oral e a escrita: apresentação de um procedimento", traduzido por Rojo e Cordeiro (2004). Essa tradução se destacou no contexto acadêmico e em alguns cursos de formação continuada, mas até hoje não foi apropriada por muitos docentes que atuam na educação básica.

Os Parâmetros Curriculares Nacionais (PCN), documento parametrizador do ensino fundamental de língua portuguesa, publicados nos anos 80, já propunham o texto como unidade básica para o ensino dessa língua, associado à noção de gênero (BRASIL, 1998), e já estabeleciam como critérios de avaliação da aprendizagem o atendimento às condições de produção textual (papéis assumidos pelos interlocutores, conhecimentos presumidos do interlocutor, restrições impostas pelo lugar de circulação dos textos) e ao projeto textual em desenvolvimento (BEZERRA e REINALDO, 2017).

Conforme Bezerra e Reinaldo (2017, p.1), as indicações para o trabalho com o texto, sobretudo nos PCN, encontraram no conceito genebrino de sequência didática um modo de efetivação. Entretanto, a disseminação desse conceito gerou entendimentos diferentes e, consequentemente, usos variados. Considerando a importância que a SD assume no trabalho efetivo com os gêneros textuais em sala de aula, este artigo se propõe a analisar a relação existente entre a concepção docente sobre SD e a produção desta por uma professora do Ensino Fundamental da rede pública de Ensino da cidade de Campina Grande (PB).

O material para a investigação foi gerado em uma pesquisa ${ }^{3}$ mais ampla que se insere no âmbito da Linguística Aplicada, pois tem compromisso com o social, uma vez que busca estudar um objeto derivado do cotidiano escolar e contribuir para a compreensão da problemática do planejamento de sequências didáticas na escola básica. Além disso, tal pesquisa estuda o objeto dentro do contexto histórico, vinculado ao seu contexto de produção dos dados.

Seguimos a abordagem qualitativa de pesquisa, com base documental interpretativista. Quanto ao tipo, classificamos a presente pesquisa como um estudo de caso, uma vez que envolve um estudo profundo de um objeto de maneira que se permita o seu amplo e detalhado

\footnotetext{
${ }^{3}$ Os dados analisados neste estudo fazem parte do corpus de uma pesquisa maior que está em andamento e que resultará na dissertação do mestrado, desenvolvida no Programa de Pós-Graduação em Linguagem e Ensino (POSLE-UFCG), intitulada de "O ensino dos gêneros textuais em curso de formação continuada: (re) configurando práticas de planejamento para o ensino de Língua Portuguesa". Por sua vez, esta pesquisa maior se vincula ao projeto de pesquisa "Gêneros Textuais como objeto de ensino: perspectivas teóricas e instrumentos didáticos", coordenado por duas professoras do referido Programa.
} 
conhecimento (GIL, 1999). Assim, este trabalho provém da análise da concepção de uma docente do Ensino Fundamental, colaboradora da pesquisa, e da SD construída por ela, em específico, para uma reflexão mais aprofundada sobre a concepção de SD e as atividades construídas para o trabalho com os gêneros textuais na escola.

Considerando o nosso objetivo, justificamos a opção pelo estudo de caso porque nos possibilita focalizar uma situação específica, buscando compreender as singularidades dos dados gerados a partir da produção de trabalho docente, mediante a SD como um instrumento metodológico integrador do Projeto do ensino de língua portuguesa. Interessa-nos um maior entendimento do dizer e do fazer da professora para a compreensão dos elementos capazes de gerar a apropriação dos gêneros textuais no Ensino Fundamental.

A análise desenvolvida neste trabalho se dará a partir de um questionário, com perguntas que abordam o conceito de SD e questões relativas a tal procedimento, respondido por uma professora ${ }^{4}$ da rede municipal da educação básica da cidade de Campina Grande, Paraíba. Essa professora participou de um curso de formação continuada (2016) em formato de extensão, intitulado "Didatização de gêneros textuais no Ensino Fundamental". 5 Além do questionário, a análise contempla atividades que compõem uma sequência didática elaborada por essa docente e que se destina a alunos do $1^{\mathrm{o}}$ ano do Ensino Fundamental e foi aplicada nas aulas da disciplina de Língua Portuguesa, durante os meses de outubro a dezembro de 2016.

Assim, temos, no presente estudo, duas categorias de análise: o dizer/concepção da professora sobre sequência didática; e o planejamento das atividades da sequência didática feito por ela.

O questionário aplicado com a professora é formado por quatro perguntas discursivas que se referem ao conceito e ao planejamento da sequência didática. Para este trabalho, fizemos um recorte, de modo que só iremos analisar a resposta dada à pergunta: "O que você entende por Sequência Didática?".

\footnotetext{
${ }^{4}$ A professora colaboradora é licenciada em Pedagogia, possui mestrado profissional em formação de professores, pela UEPB, e trabalha na rede municipal de ensino de Campina Grande-PB.

${ }_{5} \mathrm{O}$ curso objetiva oferecer formação continuada, no formato de extensão, sobre didatização de gêneros textuais para professores que atuam em escolas públicas do Ensino Fundamental da Educação Básica da rede Municipal de Ensino da cidade de Campina Grande e alunos da Graduação em Letras e Pedagogia. Ele é realizado por professores da Unidade Acadêmica de Letras e de Educação da Universidade Federal de Campina Grande e em parceria com a prefeitura Municipal de Campina Grande. O curso possui um caráter predominantemente prático que contempla reflexões teóricas sobre gêneros textuais, o processo de didatização e elaboração de sequência didática de gênero (SDG), o ensino de gêneros textuais e eixos de ensino de Língua Portuguesa e a análise de propostas de atividades didáticas com foco no ensino dos eixos de leitura, escrita e análise linguística.
} 
$\mathrm{O}$ artigo se fundamenta, teoricamente, em pesquisas desenvolvidas no âmbito dos estudos do Interacionismo Sociodiscursivo (NOVERRAZ; SCHNEUWLY e DOLZ, 2004; BRONCKART, 1999; MACHADO e CRISTOVÃO, 2009; COSTA HÜBES, 2014, MIRANDA, 2015; BARROS e CORDEIRO, 2017; BEZERRA e REINALDO, 2017, entre outros) e se organiza em quatro seções: em um primeiro momento, abordamos o conceito de gêneros à luz do ISD; em seguida, tecemos considerações sobre o conceito de SD; posteriormente, apresentamos a relação existente entre a concepção docente de SD e a produção de tal sequência por uma docente do Ensino Fundamental. Por fim, apresentamos as considerações finais.

\section{Considerações sobre gêneros textuais e Sequências Didáticas}

É certo que, nas últimas décadas, os gêneros textuais adentraram as escolas e salas de aula de todo o Brasil. Todavia, é necessário ainda discutir a noção de gênero, uma vez que há diferentes correntes teóricas que atribuem sentidos diversos ao conceito de gêneros, implicando diretamente na prática docente e na construção de diferentes suportes metodológicos.

Dessa forma, e considerando as diferentes vertentes teóricas que tratam sobre os gêneros, ancoramos este trabalho na perspectiva dos estudos do Interacionismo Sociodiscursivo defendido por Bronckart e outros autores. O ISD retoma teorias de Vygotsky e de Bakhtin, a partir de outro enfoque, e entende que a linguagem surge a partir da diversidade e complexidade das diferentes práticas, o que acarreta as adaptações da linguagem e gera espécies de textos diferentes. Ao nos expressarmos, seja de forma oral ou escrita, estamos lançando mão de gêneros, entretanto, é necessário conhecer bem os gêneros para que possamos usá-los conscientemente e com intencionalidade.

Sobre a necessidade de conhecer os gêneros textuais, Bronckart (1999, p.48) diz que "conhecer um gênero de texto também é conhecer suas condições de uso, sua pertinência, sua eficácia, ou de forma mais geral, sua adequação em relação às características desse contexto social.” (BRONCKART, 1999, p. 48).

Ao compreender os gêneros como formas textuais relativamente consolidadas que estão vinculadas a diversas atividades (familiar, jornalística, publicitária, acadêmica, jurídica, literária), entendemos que, antes de chegar à escola, vamos estabelecendo contato com os 
gêneros textuais. Assim, de forma intuitiva, vamos construindo conhecimentos sobre os gêneros e suas regras, desde que nascemos. Todavia, mesmo que alguns gêneros (mais informais) sejam aprendidos por nós, sujeitos, durante nosso dia a dia, é necessário aprender outros gêneros textuais. E sendo a escola a maior agência de letramentos, cabe a tal instituição o papel de ensinar os gêneros "mais formais" aos alunos, permitindo que tenham contato com tais gêneros e possam compreendê-los, dominá-los e usá-los em situações comunicativas efetivas.

Diante da incumbência de ensinar os gêneros mais formais, a escola, mais precisamente o professor, sente dificuldade no processo de planejamento e de "aplicar" os conhecimentos teóricos durante o seu trabalho. Assim, o processo de transposição didática, a nosso ver, não é efetivado como deveria ser. Sobre transposição didática, é válido destacar o conceito elaborado por Machado e Cristovão (2009), a partir dos estudos de Bronckart e da "Escola de Didática" francesa. Para as referidas autoras,

o termo transposição didática não deve ser compreendido como a simples aplicação de uma teoria científica qualquer ao ensino, mas como o conjunto das transformações que um determinado conjunto de conhecimentos necessariamente sofre, quando temos o objetivo de ensiná-lo, trazendo sempre deslocamentos, rupturas e transformações diversas a esses conhecimentos. (MACHADO e CRISTOVÃO, 2009, p.130)

Assim, transpor didaticamente um conhecimento é torná-lo ensinável e aprendido. Para isso ocorrer, há escolhas (teóricas/metodológicas), mudanças, quebras, transformações. Essas transformações acontecem em três níveis: no primeiro, o "conhecimento científico" sofre mudanças e se torna "conhecimento a ser ensinado"; no segundo, o conhecimento a ser ensinado se transforma e passa ser "conhecimento efetivamente ensinado". Este, por fim, passa por outra mudança e se constitui em "conhecimento efetivamente aprendido" (MACHADO e CRISTOVÃO, 2009).

A transposição didática é complexa e permeada por dificuldades. Machado e Cristovão (2009) apontam alguns dos aspectos que dificultam esse processo, dentre os quais podemos destacar: a seleção dos conteúdos a serem ensinados, que não devem ficar na esfera do senso comum/ideologia; o fenômeno da dogmatização de noções que são selecionadas para o 
ensino, tornando-as verdades absolutas; a compartimentalização dos conteúdos/noções selecionados e os riscos de evidenciar incoerências globais na proposta oficial, entre outros.

Toda essa problemática gera dúvidas e dificuldades e não permite que o processo de transposição didática seja efetivado de forma coerente e eficaz. Neste ínterim, surge a sequência didática como um caminho viável para transpor didaticamente um conteúdo.

Dolz, Noverraz e Schneuwly (2004, p. 97), como foi dito antes, definem uma sequência didática como "um conjunto de atividades escolares organizadas, de maneira sistemática, em torno de um gênero textual oral ou escrito". Desse modo, as sequências didáticas são consideradas um conjunto de tarefas sequenciadas utilizadas para se ensinar um dado conteúdo ou objeto. Constituem-se como uma forma alternativa de material didático, que para se tornarem mais produtivas devem contemplar apenas um gênero textual e poucos objetos de ensino e devem ajudar o aluno a dominar um determinado gênero textual, utilizando-o de maneira adequada em determinada situação de comunicação, desenvolvendo, assim, as capacidades de linguagem que estão envolvidas na produção de cada gênero.

O objetivo das sequências didáticas é "fornecer aos alunos todas as informações necessárias para que conheçam o projeto comunicativo visado e a aprendizagem de linguagem a que está relacionado" (NOVERRAZ, DOLZ E SCHNEUWLY, 2004, p. 97). Assim, o trabalho com sequência didática deve propiciar todas as informações e condições para que os alunos compreendam o gênero textual estudado dentro das condições de produção.

Para tanto, concordamos com Barros e Cordeiro (2017) e Noverraz, Dolz e Schneuwly, (2004), quando afirmam que,para o sucesso da Sequência Didática de Gêneros (SDG), é necessário levar em consideração alguns princípios teóricos subjacentes ao procedimento. Entre esses, merecem destaque: a abordagem da multiplicidade de formas de realização da língua - em gêneros de texto; a concepção de avaliação formativa; a busca pela autonomia do aprendiz; a diversidade das atividades; tarefas e dispositivos didáticos; a abordagem da complexidade das práticas de linguagem, o foco na consciência ampla do comportamento linguístico do aluno (na escolha das palavras, organização do conteúdo, etc), a perspectiva construtivista e interacionista da elaboração dos módulos de ensino, entre outros.

Sobre as partes de uma sequência didática, Dolz, Noverraz e Schneuwly (2004, p.98) mostram um esquema com quatro partes: apresentação da situação, produção inicial, módulos 
e produção final. A apresentação da situação, como o próprio nome já diz, é a descrição/apresentação do que os alunos irão estudar e produzir. A produção inicial, que é o primeiro texto, oral ou escrito, produzido pelo aluno e correspondente ao gênero trabalhado e que permite ao professor refletir sobre o que deve ser trabalhado com os alunos e quais capacidades estes precisam desenvolver. Os módulos correspondem às atividades e exercícios sistematizados realizados com os alunos, a fim de eles superarem as dificuldades expostas na produção inicial. E, por último, a produção final, na qual o aluno coloca em prática os conhecimentos adquiridos durante o processo e que serve, também, para que tanto o aluno quanto o professor possam refletir e avaliar todas as ações desenvolvidas ao longo da sequência.

Como bem ressaltam Barros e Cordeiro (2017), com as quais concordamos, na metodologia de ensino das sequências didáticas não basta apenas apresentar aos alunos um exemplar de gêneros, fazer perguntas de interpretação e pedir que o aluno produza um dado gênero textual, como se observa em muitas salas de aula da educação básica e em livros didáticos de Língua Portuguesa. No procedimento da SDG, é necessário, segundo as autoras, um trabalho sistematizado, a fim de fornecer as informações e conhecimentos necessários para que os alunos possam se apropriar de uma 'determinada prática linguageira', não se tornando apenas um decodificador de textos ou um 'preenchedor de linhas textuais'. Assim, o desenvolvimento das oficinas deve levar o aluno a agir com e pela linguagem (BARROS e CORDEIRO, 2017).

É necessário compreender as sequências didáticas e a importância de trabalhar os gêneros de forma mais sistemática, considerando as condições de produção e de uso, e permitindo que o aluno possa compreendê-los, apropriar-se deles, produzi-los e desenvolver as capacidades de linguagem que são requeridas em uma determinada situação de interação.

\section{Concepção e planejamento de uma SD por uma professora do Ensino Fundamental:}

\section{(im)possíveis articulações}

Nesta parte do artigo, apresentamos a análise do corpus da pesquisa, contemplando o conceito de sequência didática, o planejamento e a SD elaborados pela professora colaboradora da pesquisa. 


\section{O conceito de SD segundo a visão da professora colaboradora}

Em função do espaço destinado ao presente artigo, consideramos pertinente analisarmos apenas uma pergunta do questionário referente ao conceito de sequência didática, com o intuito de verificarmos como a docente colaboradora da pesquisa concebe tal procedimento didático.

A questão em análise indaga a professora sobre o que ela entende por SD. A resposta dada pela docente foi: "SD- são sequências metodológicas ordenadas em ordem crescente de dificuldade para apreensão do conteúdo, feita para ensino de determinados conteúdos ou execução de projetos".

Podemos perceber que o conceito de SD da professora é bem genérico centrado na ideia de uma prática metodológica para o trabalho com os conteúdos, levando em conta as dificuldades dos alunos, não fazendo menção ao gênero textual a ser trabalhado durante o procedimento da SD.

A nosso ver, a definição produzida pela professora colaboradora se aproxima do conceito de Antoni Zabala (1998), que define sequência didática como

\footnotetext{
um conjunto de atividades ordenadas, estruturadas e articuladas para a realização de certos objetivos educacionais, que têm um princípio e um fím conhecidos tanto pelos professores como pelos alunos (...) têm a virtude de manter o caráter unitário e reunir toda a complexidade da prática, ao mesmo tempo em que (...) permitem incluir as três fases de toda intervenção reflexiva: planejamento, aplicação e avaliação (ZABALA, 1998 p.18).
}

Entendemos que a sequência didática não pode ser reduzida simplesmente a um procedimento com certas etapas a serem preenchidas com atividades, não se trata de um mero esquema de fases, como bem ressaltam Barros e Cordeiro (2017). É importante que a SD tenha bases teóricas e objetivos bem claros, a fim de que o aluno possa realmente se apropriar do gênero textual selecionado para ser explorado em sala de aula.

Com isso, não queremos dizer que o conceito apresentado pela professora deva ser desconsiderado. Ele apenas difere em parte da perspectiva do ISD, comumente aceito pelos documentos parametrizadores do Ensino de Língua Portuguesa. A concepção de SD da professora colaboradora da pesquisa, embora não contemple os gêneros textuais, diferindo do grupo genebrino que concebe SD como "um conjunto de atividades escolares organizadas, de maneira sistemática, em torno de um gênero textual oral ou escrito" (NOVERRAZ; 
SCHNEUWLY; e DOLZ, 2004, p.97), considera alguns aspectos relevantes a exemplo da percepção das dificuldades apresentadas pelos aprendizes em relação aos conteúdos, o que, a nosso ver, tem relação com os módulos.

Além disso, percebemos no conceito de Sequência Didática da docente participante da nossa pesquisa, a proximidade com o uso da metodologia dos projetos, tão defendida nos PCNs de Língua Portuguesa. Conforme Cordeiro e Barros (2017), o trabalho com SDG deve ter o caráter de projeto de ensino com objetivos que se articulem e se complementem.

Na perspectiva genebrina, o conteúdo está relacionado ao gênero e este é visto como um megainstrumento, usado como ferramenta para o trabalho com o desenvolvimento das capacidades de linguagem envolvidas na produção de um texto (capacidades de ação discursiva e linguístico-discursivas). Ainda segundo Barros e Cordeiro (2017), o aluno precisa perceber a unidade e a integração entre as oficinas, os seus objetos e as atividades que as compõem.

Assim, entendemos que é importante no procedimento da sequência didática possibilitar uma série de atividades didáticas que promovam o desenvolvimento da capacidade comunicativa dos alunos por meio da leitura e da escrita, independentemente da nomenclatura ou concepção terminológica.

Para uma maior clareza sobre a concepção de sequência didática analisada, recorremos à reflexão feita por Bezerra e Reinaldo (2017) acerca da diferença entre o conceito de SD no âmbito da didática e no da didática da Língua. Para essas autoras, o conceito de SD na área do conhecimento da didática foi divulgado no Brasil, a partir da obra "A Prática Educativa: como ensinar”, de Antoni Zabala, publicada em 1998.

De acordo com Zabala, a SD, ou sequência de atividade de ensino/aprendizagem, é uma maneira de encadear e articular as diferentes atividades ao longo de uma unidade didática. Assim, poderemos analisar as diferentes formas de intervenção segundo as atividades que se realizam e, principalmente, pelo sentido que adquirem quanto a uma sequência orientada para a realização de determinados objetivos educativos (ZABALA, 1998, p.20). Interpretando o conceito de Zabala, as autoras afirmam, em outros termos, que a SD implica atividades sucessivas e inter-relacionadas com vistas a atingir o objetivo estabelecido na unidade de ensino. Esse objetivo remete à construção de conhecimento, característica inerente ao ensino produtivo, defendido por esse autor (BEZERRA e REINALDO, 2017). 
Já a didática de línguas, segundo Bezerra e Reinaldo (2017, p. 9), recorre, entre outras ferramentas, à da sequência didática, cujo conceito, proposto por Dolz, Noverraz e Schneuwly (2004[2001]), remete a "um conjunto de atividades escolares organizadas, de maneira sistemática, em torno de um gênero textual oral ou escrito" (p.97). Ou seja, o foco da SD é o ensino de gênero, com o intuito de possibilitar ao aluno sua apropriação, de modo que ele venha a escrever ou falar adequadamente numa certa situação comunicativa.

É importante ressaltar que os dois conceitos, no nosso entender, embora tenham semelhanças, são distintos pela generalidade de um, no caso o conceito de SD apresentado por Zabala, e a especificidade do outro conceito, o apresentado pelo grupo genebrino, que foca o gênero textual com vistas ao trabalho com a língua portuguesa e, em especial, com a produção escrita.

Diante do exposto, fica evidente a importância de se ter clareza sobre o que é uma SD para poder planificá-la e planejá-la no espaço da sala de aula. A SD da professora colaboradora da pesquisa demonstra que, embora ela não tenha se apropriado das discussões da didática da língua, tem clareza sobre o que é uma SD, no âmbito dos estudos da Didática.

Feitas essas considerações, passaremos a analisar o planejamento da SD didática realizada pela docente com um olhar voltado para a relação entre essa atividade e a concepção dela sobre SD, anteriormente apresentada.

\section{Planejamento e SD elaborados pela Professora do EF}

O planejamento da SD da professora colaboradora da pesquisa é feito considerando o gênero textual tirinha e se divide em três partes que são: atividade diagnóstica, o plano de ensino e cronograma de atividades. Essa forma de organização do planejamento da SD seguiu as orientações dadas no Curso de Extensão "Didatização de Gêneros Textuais", já mencionado neste artigo, do qual a professora participou e no qual essa sequência foi produzida: primeiro, as professoras participantes elaboraram a atividade diagnóstica, em seguida fizeram o plano de ensino e, depois, as atividades que constituem as SD, conforme veremos a seguir. 


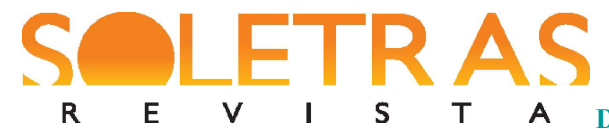

\section{Atividade Diagnóstica}

A atividade diagnóstica do gênero contempla o estudo de uma tirinha da Turma da Mônica e é composta por perguntas de compreensão leitora e aspectos linguísticos e visuais do texto estudado.

Escola Municipal:

Campina Grande,

Sou:

Professora: $-1^{\mathrm{o}}$ ano - tarde

Cascão está em perigo e deve ser socorrido rapidamente, pois é uma criança. A partir do que você observa na tirinha, responda:
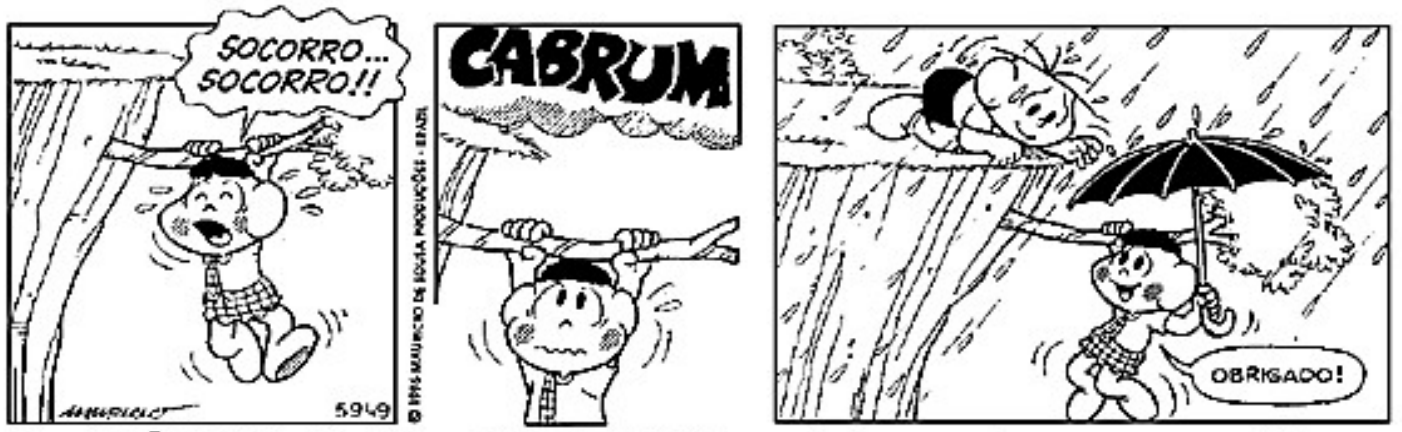

Copyright (C)1999 Mauricio de Sousa Produộ́es Ltda. Todos os direitos reservados.

5949

1 -Você conhece os personagens que aparecem na tirinha?

2-Quem são os autores das tirinhas?

3-Você já viu esse tipo de texto em algum lugar:

Onde?

4-Pra que servem os balões nas tirinhas acima?

5- O que a palavra CABRUM representa no texto?

6- Por que na palavra SOCORRO do primeiro quadrinho, as letras aparecem diferentes da palavra obrigado no terceiro quadro ( $1^{\mathrm{a}}$ tira $)$

7- Descreva a situações de perigo em que Cascão se envolveu:

8-Do quê Cascão tem medo?

9- Na tirinha de $\mathrm{n}^{\mathrm{o}} 1$ Cascão pedia Socorro nos dois primeiros quadrinhos. O motivo é o mesmo?

10-Que fenômeno climático acontece na tirinha?

11-O que aconteceu no último quadrinho?

11-A ajuda de Cebolinha no terceiro quadrinho deixou Cascão agradecido por quê?

12- Se você fosse contar essa história a alguém, como você faria?

Fonte: Atividade diagnóstica elaborada pela professora colaboradora da pesquisa

A atividade acima revela que a professora explora questões de leitura de diversas formas, indo de questões objetivas, a exemplo de "Que fenômeno climático Cascão tem medo?", cuja resposta é evidenciada através da representação das gotas de chuva e do uso do 
guarda-chuva, questões subjetivas, como “você já viu este tipo de texto em algum lugar?", até questões mais inferenciais e interpretativas do tipo "Se você fosse contar essa história a alguém, como faria?".

A nosso ver, a atividade apresenta avanços em relação a muitas atividades de leitura que focam apenas na decodificação de elementos linguísticos presentes na superfície do texto, em detrimento de questões inferenciais definidas como "questões mais complexas que exigem conhecimento textual e outros, sejam pessoais, contextuais, enciclopédicos, bem como regras inferenciais e análise crítica para busca de respostas" (MARCUSCHI, 2001).

Entretanto, em relação à escrita, o gênero tirinha é praticamente inexplorado, o que, a nosso ver, é um ponto negativo, uma vez que a leitura e a escrita são duas modalidades que devem ser trabalhadas de modo integrado. Além disso, o plano de ensino que é produzido posteriormente pela professora contempla uma atividade escrita.

Apesar da falha identificada, não podemos obscurecer que a atividade diagnóstica, em análise, é relevante e capaz de levar a professora a avaliar o nível da turma e a tomar posições, posteriormente, concretizadas em um planejamento de ensino do gênero textual selecionado, como podemos verificar no plano a seguir.

\section{Plano de Ensino}

O plano de ensino do gênero textual tirinha, elaborado pela professora colaboradora da pesquisa para uma turma do $1^{\circ}$ ano do Ensino Fundamental, contempla os seguintes elementos: objetivos (geral e específicos); conteúdos; metodologia; recursos e avaliação.

Plano de ensino: Gênero textual- Tirinha

Público alvo: Turma do $1^{\circ}$ ano

\section{OBJETIVO GERAL:}

Trabalhar o gênero textual tirinha, assim como estratégias de leitura para compreender e interpretar esse gênero. 


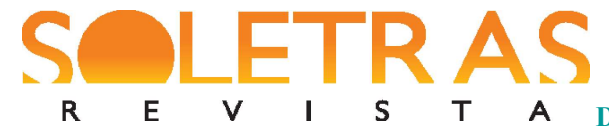

$\mathbf{R}$
S

DOSSIÊ-N. 35 - 2018.1 - MARIA FÁTIMA ALVES

VANDERLÉIA LUCENA MEIRA

\section{OBJETIVOS ESPECÍFICOS:}

1- Reconhecer e compreender as características do gênero tirinha

1.1 Reconhecer as condições de produção (função, interlocutores, suporte) e estrutura composicional do gênero tirinha.

1.2 Compreender conteúdo das tirinhas através da leitura do texto verbal e não verbal.

1.3 Reconhecer os recursos gráficos utilizados para facilitar a compreensão do gênero.

1.4 Estudar os elementos icônicos da tirinha: a forma dos balões, tipos de letras, os sinais usados nos lugares das letras, as onomatopeias e sua utilidade para produção de sentidos.

2-Utilizar as estratégias de leitura para a compreensão do gênero tirinha

2.1 Localizar informações implícitas e explícitas nos textos verbais/não verbais veiculados na tira.

2.2 Utilizar as estratégias de leitura (seleção cognitiva, antecipação, inferência e verificação).

2.3 Ler outros textos não verbais, com vistas a apreensão das marcas gráficas características dos textos não verbais (expressões textuais, marcas icônicas).

3- Ampliar os conhecimentos sobre o conteúdo do $4^{\circ}$ eixo temático contextualizado nas tirinhas.

4- Produzir textos verbais representando diálogos na tirinha.

5- Fazer produção inicial e autônoma de tirinha

\section{CONTEÚDOS}

- A tirinha (estrutura composicional do gênero);

- Onomatopeias;

- Tipos de balões;

- Sílabas complexas na escrita das onomatopeias;

- Letras maiúsculas (Inicial nos nomes dos personagens das tirinhas);

- Troca de $\mathbf{r}$ por $\mathbf{I}-\mathbf{r}$ brando;

- Estratégias de leitura (seleção cognitiva, antecipação, inferência e verificação);

- Compreensão e interpretação textual;

- Leitura de histórias não verbais;

- Diálogos da tirinha;

\section{METODOLOGIA}

Aplicação de atividades diagnósticas sobre o gênero textual a ser trabalhado; análise dessas atividades para construção do plano de ensino sobre o gênero.

Levar tirinhas para realizar, junto ao professor uma leitura coletiva das mesmas. Pesquisa para 
trazerem exemplares de tirinhas; produção de cartaz com as tiras trazidas e outras ampliadas para destaque dos elementos gráficos do gênero. Observação coletiva dos suportes que fixam as tirinhas; exercícios em folhas digitadas/xerocadas sobre o gênero.

Distribuição de tirinhas para lerem em casa e nas horas vagas (caixa que ficará disponível na sala de aula para leitura deleite); Ordenação de quadros para compor a tira; textualização de tirinhas (oral e escrita), audição ou imitação de sons que são representados pelas onomatopéias; aula expositiva com tipos de balões; Construir o jogo de onomatopéias. Atividades com o texto não verbal e os balões para as crianças construírem diálogos coerentes com as imagens; Retextualizações coletivas (orais) e depois individuais (escritas)de tirinhas. Exibição de vídeo da turma da Mônica pra reconhecimento das características dos personagens.

*Composição de um "gibi" de tirinhas com as produções da turma para presenteá-los individualmente no final da sequência/ano. (se conseguirmos reescrever)

\section{RECURSOS}

$[\ldots]$

Folhas para escrita das atividades, suportes textuais das tirinhas (livros, gibis, jornais), cartazes, slides, fichas com tirinhas; palitoches com algumas onomatopeias; etc.

\section{AVALIAÇÃO}

A avaliação deverá ser feita através da observação e o empenho das crianças na realização das atividades, assim como seu envolvimento em todas as etapas desse plano de ensino.

Quadro 1-Plano de Ensino elaborado pela professora colaboradora da pesquisa.

O plano, a nosso ver, é relevante porque abrange a compreensão das características e da estrutura composicional do gênero tirinha, o reconhecimento das condições de produção (função, interlocutores, suporte), a linguagem verbal e não verbal, o estilo linguístico, os elementos gráficos e sua influência na construção do sentido, o desenvolvimento das estratégias de leitura globais e específicas do gênero, a apropriação dos conteúdos referentes aos direitos humanos ( $4^{\circ}$ eixo temático definido pela secretaria municipal de educação da cidade de Campina Grande) e a produção de tirinhas.

Apresentaremos, a seguir, uma síntese da SD elaborada pela docente, contemplando objetivos e propostas de atividades. 
VANDERLEIA LUCENA MEIRA

\begin{tabular}{|c|c|}
\hline ORGANIZAÇÃO DA SD & AÇÕES DESCRITAS PELA PROFESSORA \\
\hline ATIVIDADE DIAGNÓSTICA & $\begin{array}{l}\text { Aplicação de atividades diagnósticas sobre o } \\
\text { gênero textual a ser trabalhado; análise dessas } \\
\text { atividades para construção do plano de ensino } \\
\text { sobre o gênero. }\end{array}$ \\
\hline $\begin{array}{l}\text { Módulo I } \\
\text { Trabalho com a leitura e com aspectos do } \\
\text { gênero estudado. }\end{array}$ & $\begin{array}{l}\text { Leitura coletiva de tirinhas junto aos alunos. } \\
\text { Pesquisa para trazerem exemplares de tirinhas; } \\
\text { produção de cartaz com as tiras trazidas e } \\
\text { outras ampliadas para destaque dos elementos } \\
\text { gráficos do gênero. }\end{array}$ \\
\hline $\begin{array}{l}\text { Módulo } 2 \\
\text { Trabalho com a leitura e com aspectos do } \\
\text { gênero estudado. }\end{array}$ & $\begin{array}{l}\text { Observação coletiva dos suportes que fixam as } \\
\text { tirinhas; exercícios em folhas } \\
\text { digitadas/xerocadas sobre o gênero. } \\
\text { Distribuição de tirinhas para lerem em casa e } \\
\text { nas horas vagas (caixa que ficará disponível na } \\
\text { sala de aula para leitura deleite); } \\
\text { Ordenação de quadros para compor a tira; } \\
\text { textualização de tirinhas (oral e escrita), }\end{array}$ \\
\hline $\begin{array}{l}\text { Módulo } 3 \\
\text { Trabalho com os elementos linguísticos e } \\
\text { gráficos que compõem o gênero tirinha, }\end{array}$ & $\begin{array}{l}\text { Audição ou imitação de sons que são } \\
\text { representados pelas onomatopeias; aula } \\
\text { expositiva com tipos de balões; Construção do } \\
\text { jogo de onomatopeias. }\end{array}$ \\
\hline $\begin{array}{l}\text { Módulo } 4 \\
\text { Atividades de produção textual (orais e } \\
\text { escritas) }\end{array}$ & $\begin{array}{l}\text { Atividades com o texto não verbal e os balões } \\
\text { para as crianças construírem diálogos } \\
\text { coerentes com as imagens; } \\
\text { Retextualizações coletivas (orais) e depois } \\
\text { individuais (escritas) de tirinhas. }\end{array}$ \\
\hline $\begin{array}{l}\text { Módulo } 5 \\
\text { Trabalhando a temática e os personagens das } \\
\text { tirinhas estudadas (considerando que uma boa }\end{array}$ & $\begin{array}{l}\text { Exibição de vídeo da turma da Mônica pra } \\
\text { reconhecimento das características dos } \\
\text { personagens. }\end{array}$ \\
\hline
\end{tabular}




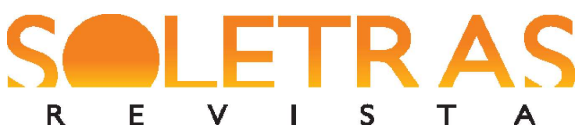

VANDERLÉIA LUCENA MEIRA

\begin{tabular}{|l|l|}
\hline parte das tirinhas é da turma da Mônica) & \\
\hline Produção Final & $\begin{array}{l}\text { Composição de um "gibi" de tirinhas com as } \\
\text { produções da turma para presenteá-los } \\
\text { individualmente no final da sequência/ano (se } \\
\text { conseguirmos reescrever). }\end{array}$ \\
\hline
\end{tabular}

Quadro 2- síntese comparativa dos objetivos e da metodologia apresentada no Plano de Ensino pela professora colaboradora e das partes da SD, de acordo com o grupo genebrino.

Neste quadro, temos, na primeira coluna, a base da organização das partes de uma SD defendida pelo grupo genebrino e que pode ser encontrada em NOVERRAZ, DOLZ E SCHNEUWLY (2004). A segunda coluna apresenta as ações descritas na metodologia do plano de ensino construído pela professora, ou seja, a explicitação das atividades planejadas por ela que compõem a SD analisada neste estudo.

As ações descritas na metodologia se interligam com as atividades propostas no cronograma, cumprindo o que a professora prescreve no planejamento. No nosso entender, o que a docente denomina de metodologia no plano de ensino são atividades desenvolvidas que equivalem aos módulos na proposta do ISD (NOVERRAZ, DOLZ E SCHNEUWLY, 2004). Embora as atividades estejam em consonância com o que o grupo de Genebra defende, a professora não usa os termos característicos próprios da proposta de SD defendida pelo grupo genebrino, a exemplo da apresentação do tema e da produção inicial, mesmo que o foco tenha sido mais a leitura. Todavia, isso não prejudica a qualidade das atividades planejadas, pois, como sabemos, já há muitos pesquisadores trabalhando a SD adaptada à realidade das escolas brasileiras, a exemplo de Costa-Hubes (2014), que faz adaptações das SD para os anos iniciais das escolas brasileiras, acrescentando-lhes dois módulos: o de reconhecimento do gênero e o de circulação dos gêneros. Este acréscimo se deu devido ao fato de que os alunos brasileiros estão inseridos em um sistema de ensino que não privilegia as aulas de produção textual da mesma forma que a Suíça. A alteração na SD adaptada/proposta por Costa-Hubes tem como finalidade desenvolver com os alunos atividades que contemplem a pesquisa, a leitura e a análise linguística de textos do gênero selecionado (COSTA-HUBES, 2014)

A partir do exposto, podemos afirmar que, embora a concepção da docente sobre SD esteja mais adequada ao conceito de SD, no âmbito da Didática, as atividades propostas por ela comungam com a metodologia da didática da língua, defendida pelo grupo de Genebra.

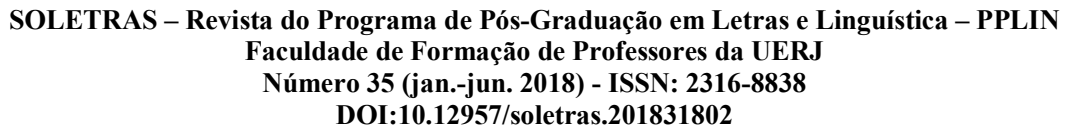


Em outros termos, a professora compreende a proposta da sequência didática, uma vez que desenvolve bem as atividades, trabalhando os conteúdos de forma producente, relacionando-as com os objetivos a que se propõe e tendo o gênero estudado como um megainstrumento.

Assim, mesmo não demonstrando na sua concepção de SD bases teóricas ligadas mais diretamente aos estudos da linguagem/língua, a professora, no planejamento das atividades, mostra o domínio do conceito de SD para o ensino de Língua, por meio dos gêneros textuais. Ao organizar as atividades, a professora remete à proposta de $\mathrm{SD}$ apresentada pelo grupo do ISD e sistematiza essas atividades em torno de um gênero textual.

Ademais, é necessário destacar que a professora colaboradora está em processo de apropriação dos conceitos e propostas sobre gêneros textuais e sequências didáticas, inclusive aqueles defendidos pelo grupo de Genebra, que constituem as bases teóricas do curso de extensão e, também, deste trabalho.

\section{Considerações finais}

Os resultados da análise aqui empreendida nos levam a refletir sobre o conceito de sequência didática no âmbito da didática e da didática da língua, bem como sobre a importância da metodologia de ensino de língua mediante o uso de sequências didáticas no trabalho com os gêneros textuais na educação básica. Em outros termos, um dos caminhos para se trabalhar os gêneros é utilizando as sequências didáticas como uma alternativa produtiva para desenvolver o trabalho com textos na sala de aula, de forma sistematizada e contextualizada, levando em conta os aspectos inerentes ao gênero, sua produção e, também, suas condições de circulação.

O estudo mostra que, mesmo havendo diferenças entre o conceito de sequência didática pelos docentes e a elaboração de plano de ensino e de sequência didática, por parte deles, é possível a realização de atividades producentes capazes de levar os alunos a se apropriarem dos gêneros textuais, como ilustraram as atividades propostas para o trabalho com a tirinha pela professora colaboradora da pesquisa.

Tais atividades apontam para a consciência, por parte da docente colaboradora da pesquisa, da importância de trabalhar com os gêneros na sala de aula, como também, para a relevância de entender que os gêneros permitem o desenvolvimento das capacidades de 
linguagem e que devem ser trabalhados de forma contextualizada, aliados às necessidades dos alunos, de modo a superá-las.

Conhecer bem um gênero é, também, conhecer suas condições de produção, sua finalidade e as capacidades de linguagem intrínsecas à sua produção. É necessário que os professores desenvolvam atividades e práticas docentes que levem em conta esses aspectos e que propiciem que os alunos conheçam, compreendam e utilizem os gêneros textuais de forma consciente e adequada às situações de interação e das práticas sociais das quais participam.

Por fim, os resultados apontam para a necessidade do desenvolvimento de cursos de formação continuada, a exemplo do curso de "Didatização de Gêneros Textuais, do qual a docente colaboradora desta pesquisa participou, propiciando autonomia para produzir material didático (enunciados, modelos didáticos, sequências didáticas, entre outros), à luz de teorias linguísticas sobre leitura e escrita, em particular sobre os gêneros textuais, que busquem expandir as práticas de letramento dos alunos.

Ademais, as análises feitas neste trabalho servirão de base para a reflexão durante o processo de planejamento e execução das aulas do Curso de Extensão "Didatização de Gêneros Textuais no Ensino Fundamental", uma vez que o curso se tornou uma ação contínua e, por isso, a professora participante desta pesquisa terá oportunidade de refletir sobre sua concepção e planejamento da SD, de modo a superar dificuldades apresentadas. Essa reconfiguração acontecerá a partir das reflexões feitas neste trabalho e das discussões que serão feitas durante as aulas do curso de extensão, que, nesta nova fase, enfoca o processo de didatização de gêneros textuais, articulando a leitura, escrita e análise linguística, do qual a professora participante é aluna. Nós também participamos do curso, uma de nós como professora executante e a outra como pesquisadora.

A nosso ver, o curso de formação continuada, em formato de extensão "Didatização de Gêneros Textuais no Ensino Fundamental" ocasiona efeitos positivos na formação docente, uma vez que ele permitiu que os professores produzissem atividades, refletissem teóricometodologicamente sobre elas e pudessem reconfigurá-las. Assim, os professores que participaram desse curso tiveram uma formação teórico-metodológica voltada para o ensino dos gêneros textuais nas aulas de Língua Portuguesa e, sobretudo, tiveram autonomia para 


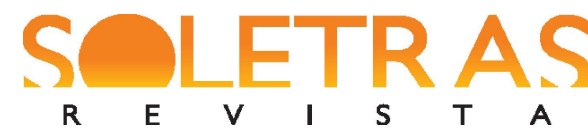

DOSSIÊ-N. 35 - 2018.1 - MARIA FÁTIMA ALVES

VANDERLEIA LUCENA MEIRA

planejar e produzir atividades e materiais didáticos com foco nos eixos do Ensino de Língua Portuguesa.

\section{Referências bibliográficas}

BARROS, E. M. D. As reconcepções do trabalho docente no processo da transposição didática de gêneros; in: ; RIOS-REGISTRO, E. S. Experiências com sequências didáticas de gêneros textuais. Campinas: Pontes, 2014, p.41-68.

BEZERRA, M. A.; REINALDO, M. A. O conceito de sequência didática no âmbito do Ensino de Língua (materna e estrangeira): da academia à escola. Campina Grande: UFCG (2017). No Prelo.

BRASIL. Parâmetros curriculares nacionais do Ensino Fundamental - anos finais. Brasília: MEC, 1998.

BRONCKART, J. P. Atividade de linguagem, textos e discursos: por um interacionismo sócio-discursivo. Trad. Anna Rachel Machado e Péricles Cunha. São Paulo: EDUC, 2003.

. Atividade de linguagem, discurso e desenvolvimento humano. Trad. Anna Rachel Machado; Maria Lucia Meirelles Matêncio. Campinas: Mercado de Letras, 2006.

. O agir nos discursos: das concepções teóricas às concepções dos trabalhadores. Trad. Anna Rachel Machado; Maria Lucia Meirelles Matêncio. Campinas: Mercado de letras, 2008. $176,2010$.

Gêneros de textos, tipos de discurso e sequências. Revista Letras, nº 40, v. 20, p.163-

BARROS, Eliana Merlin Deganutti; CORDEIRO, Glaís Sales. A validação da metodologia das sequências didáticas de gêneros sob a perspectiva do gesto didático de ativação da memória das aprendizagens. In: BARROS, Eliana Merlin Deganutti; CORDEIRO, Glaís Sales; GONÇALVES, Adair Vieira. (Orgs). Gestos didáticos para ensinar a língua: Agir docente e gêneros textuais. Campinas, SP: Pontes Editores, 2017, p. 217-248.

COSTA-HÜBES, T. C.; SIMIONI, C. A. Sequência didática: uma proposta metodológica curricular de trabalho com os gêneros discursivos/textuais. In: BARROS, Eliana M. D. de; RIOS-REGISTRO; Eliane Segati (orgs.). Experiências com sequências didáticas de gêneros textuais. São Paulo: Pontes Editores, 2014.

DOLZ, Joaquim; NOVERRAZ, Michele; SCHNEUWLY, Bernard. Sequências didáticas para o oral e a escrita: apresentação de um procedimento. In: SCHNEUWLY, Bernard; DOLZ, Joaquim. Gêneros orais e escritos na escola. Tradução de Roxane Rojo e Glaís Sales Cordeiro. Campinas, SP: Mercado das Letras, 2004, p. 95-128. 
GIL, A. C. Métodos e técnicas de pesquisa social. São Paulo: Atlas, 1999.

HILA, Cláudia Valéria Doná. Ressignificando a aula de leitura a partir dos gêneros textuais. IN: NASCIMENTO, E. L. (Org.). Gêneros textuais: da didática das línguas aos objetos de ensino. $1^{a}$. ed. São Carlos: Editora Claraluz, 2009, p.151-194.

LÜDKE, Menga. ANDRÉ, Marli E. D. A. Pesquisa em Educação: abordagens qualitativas. São Paulo: EPU, 1986.

MACHADO, Anna Rachel; CRISTOVÃO, Vera Lúcia L. A construção de modelos didáticos de gêneros: aportes e questionamentos para o ensino de gêneros. In: ABREU-TARDELLI, L.S: CRISTOVÃO, Vera Lúcia L. (Orgs.) Linguagem e educação: o ensino e a aprendizagem de gêneros textuais. Campinas: Mercado de Letras, 2009, p. 123-151.

MARCUSCHI, L. A. Compreensão de textos: algumas reflexões. In: DIONÍSIO, A. P; BEZERRA, M. A. (Orgs.). O livro didático de Língua Portuguesa: múltiplos olhares. Rio de Janeiro: Lucerna, 2001, p. 46-59.

MIRANDA, Florencia. Considerações sobre o ensino de gêneros textuais: pesquisa e intervenção. In: LEURQUIN, Eulália; COUTINHO, Maria Antónia; MIRANDA, Florencia. (organizadoras). Formação docente: textos, teorias e práticas. Campinas-SP: Mercado de Letras, 2015. Série Ideias Sobre Linguagem. p. 217-240.

ZABALA, Antoni. A prática educativa: como ensinar. Trad. Ernani F. da Rosa. Porto Alegre: ArtMed, 1998.

\title{
The didactic sequence in the Elementary School context: relations between the teaching conception and the planning of activities
}

\begin{abstract}
A didactic sequence, understood as a systematic set of activities around a given textual genre (NOVERRAZ, SCHNEUWLY and DOLZ (2004)), is an effective means to transpose textual genres in a structured way, making them teachable in effective situations of communication. This research is classified as a case study and seeks to analyze the relationship between the teaching conception and the planning of a didactic sequence by a Primary School teacher of the municipal public network of Campina Grande, State of Paraíba. The data composing the research corpus are made up of an interview with the teacher about DS and the planning of the sequence. The study is based on the work of BRONCKART (1997, 1999, 2010), MIRANDA (2015), MACHADO and CRISTOVÃO (2009), HILA (2009), The results show that the concept of DS on the part of the teacher is generic, distancing itself from the molds of the Genevan group, however the planning of the DS elaborated by the teacher explores the cartoon strip genre in a productive way, correlating the proposed objectives and suggested activities, and takes the genre as a mega instrument for working with the language.
\end{abstract}

Key-words: Teaching of Genres. Didactic transposition. Didactic sequence.

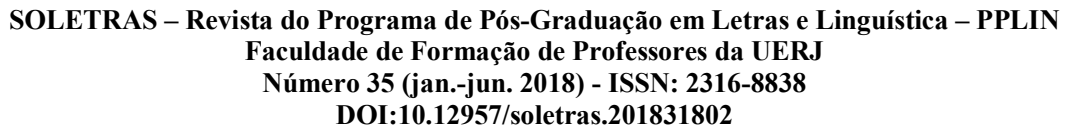




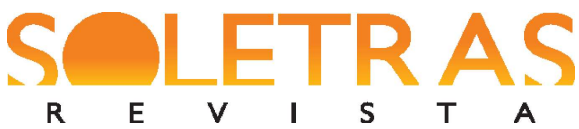

DOSSIÊ-N. 35 - 2018.1 - MARIA FÁTIMA ALVES

VANDERLÉIA LUCENA MEIRA

Recebido em 14 de dezembro de 2017.

Aprovado em 05 de janeiro de 2018. 